\title{
Pharmacology and clinical potential of guanylyl cyclase $C$ agonists in the treatment of ulcerative colitis
}

This article was published in the following Dove Press journal:

Drug Design, Development and Therapy

18 April 2013

Number of times this article has been viewed

\section{Giovanni M Pitari \\ Department of Pharmacology and Experimental Therapeutics, Thomas Jefferson University, Philadelphia, PA, USA}

Video abstract

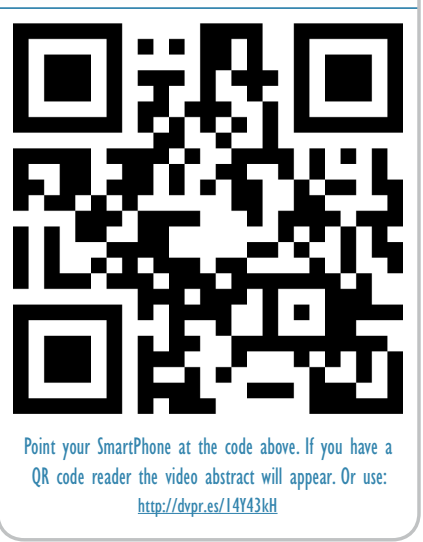

Correspondence: Giovanni M Pitari Thomas Jefferson University, 1020 Locust Street, Suite 368], Philadelphia, PA 19107, USA

Tel +l 2159555647

Fax +I 2159557006

Email gmpitari@yahoo.com

\begin{abstract}
Agonists of the transmembrane intestinal receptor guanylyl cyclase C (GCC) have recently attracted interest as promising human therapeutics. Peptide ligands that can specifically induce GCC signaling in the intestine include endogenous hormones guanylin and uroguanylin, diarrheagenic bacterial enterotoxins (ST), and synthetic drugs linaclotide, plecanatide, and SP-333. These agonists bind to GCC at intestinal epithelial surfaces and activate the receptor's intracellular catalytic domain, an event initiating discrete biological responses upon conversion of guanosine-5' -triphosphate to cyclic guanosine monophosphate. A principal action of GCC agonists in the colon is the promotion of mucosal homeostasis and its dependent barrier function. Herein, GCC agonists are being developed as new medications to treat inflammatory bowel diseases, pathological conditions characterized by mucosal barrier hyperpermeability, abnormal immune reactions, and chronic local inflammation. This review will present important concepts underlying the pharmacology and therapeutic utility of GCC agonists for patients with ulcerative colitis, one of the most prevalent inflammatory bowel disease disorders.
\end{abstract}

Keywords: inflammatory bowel disease, GCC agonists, cyclic GMP

\section{Introduction}

Ulcerative colitis (UC) is a major clinical syndrome of inflammatory bowel diseases (IBDs) and is characterized by chronic mucosal inflammation of the colon. Recurrent bloody diarrhea, tenesmus and rectal urgency are the most common symptoms for UC, but extraintestinal manifestations may also occur. ${ }^{1}$ Diagnosis of UC is mainly based on intestinal mucosa examination and tissue histopathology following colonoscopy and biopsy. ${ }^{1}$ The worldwide annual incidence of UC is $0.5-25$ per 100,000 persons, with the highest rates in Western countries and the lowest in the developing world. ${ }^{2}$ UC distributes equally among men and women, with a typical onset between 15 and 40 years of age. ${ }^{1,2}$ Although the exact pathogenetic mechanism remains unclear, it is now apparent that both environmental and genetic factors play relevant etiological roles in UC, comprising heterogeneous, multifactorial combinations giving rise to almost identical clinical syndromes. ${ }^{3,4}$ Specifically, any perturbation of the delicate balance between commensal bacteria, epithelial barrier functions, and host innate and adaptive immunity may result in chronic colonic inflammation. ${ }^{5,6}$ In the US, about 500,000 persons are affected by UC, with an annual incidence of 2-7 per 100,000 persons, representing a major clinical challenge for the absence of curative pharmacological therapies. $^{1}$

Selective ligands for guanylyl cyclase C (GCC) (Figure 1) include pathological agents (heat-stable bacterial enterotoxins; herein referred to as ST), endogenous 


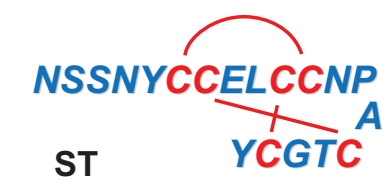

Uroguanylin $\underbrace{A}_{\text {LCGTC }}$

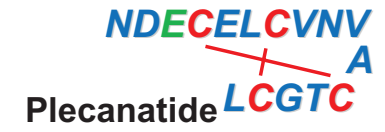

Figure I The guanylyl cyclase $C$ agonists.

Notes: Known primary amino acid structures of the agonists of guanylyl cyclase C. Residues shown in green on the structures on the right indicate amino acid substitutions in synthetic ligands compared with respective biological homologs. The amino acid sequence for ST reflects that of the heat-stable enterotoxin isoform STh produced by Escherichia coli.

hormones (guanylin and uroguanylin) and, most importantly for this review, therapeutic drugs (linaclotide, plecanatide, and SP-333) ${ }^{7-10}$ Mostly short peptides of 14-19 amino acids, these GCC agonists share close structural and functional similarities, including intrachain disulfide bonds required for biological activity, $\mathrm{pH}$ stability, protease resistance, and poor systemic bioavailability when administered orally. ST and its artificial analog, linaclotide, contain three disulfide bonds and are considered super-agonists for GCC, as they maximally activate the receptor-dependent signal transduction machinery., ${ }^{911,12}$ Plecanatide and SP-333, in turn, are synthetic analogs of the endogenous agonist uroguanylin, and together with guanylin, exhibit only two intrachain disulfide bonds. ${ }^{8,10}$ Recently, the utility of GCC agonists as IBD therapeutics has been proposed, ${ }^{13,14}$ and SP-333 is currently being developed for the treatment of UC. ${ }^{10}$ This review will discuss the pharmacological potential of GCC agonists as promising novel drugs for patients with UC.

\section{Pharmacological agonists of GCC Bacterial enterotoxins}

The first GCC ligand identified was the heat-stable enterotoxin ST (Figure 1), a diarrheagenic agent produced by intestinal pathogens such as Escherichia coli, Klebsiella sp., and Yersinia enterocolitica. ${ }^{15}$ ST comprises a family of small peptides (ranging from 17 to 53 amino acids) sharing a conserved carboxyl terminal region of 13 residues, with six cysteines forming three disulphide bridges that define the tertiary structure and physicochemical properties of the

toxin. ${ }^{7,16} \mathrm{ST}$ causes secretory diarrhea in exposed individuals by overactivating the signaling pathway of the intestinal receptor GCC, the only confirmed molecular target for ST in humans ${ }^{17}$ Accordingly, disruption of the gene encoding for GCC in mice resulted in resistance to ST-induced intestinal secretion and diarrhea. ${ }^{18,19}$ There is a general consensus that after colonizing the intestine of humans or animals for survival and growth, bacteria secrete ST to exploit the host GCC signaling and disseminate into the external environment. Infectious diarrhea caused by ST-producing bacteria is a major morbidity factor in areas of poor sanitation and crowded conditions, and remains a principal cause of travelers' diarrhea and infant mortality in developing nations. ${ }^{20}$ Despite improved mechanistic understanding, the frequency of these diarrheal diseases has not significantly changed during the past decades. ${ }^{20}$ Provocatively, the worldwide risk of travelers' diarrhea inversely correlates with the incidence of colon cancer, and developing countries appear to be protected from colorectal transformation. ${ }^{21}$ This cancer resistance has been suggested to reflect, in part, longitudinal exposure of endemic populations to enterotoxigenic infections ${ }^{22}$ and the ability of ST to regulate the cell cycle transition, and suppress proliferation of intestinal epithelial cells..$^{21,23}$ In this model, ST and the host GCC represent an evolutionary-conserved symbiotic system conferring mutual beneficial effects to microbes and mammals.

\section{Endogenous hormones}

After ST, two endogenous peptide ligands for GCC with primary amino acid sequences similar to the enterotoxin were identified. First, a substance from rat intestinal extracts that stimulated GCC signaling in human colon adenocarcinoma cells was isolated and named guanylin. ${ }^{24}$ Subsequently, a guanylin-like peptide was isolated from the urine and intestine of opossum and humans and named uroguanylin. ${ }^{25,26}$ Guanylin and uroguanylin are principally synthesized in the intestine, circulate in the bloodstream, are excreted in the urine, and induce diuresis, natriuresis, and kaliuresis, suggesting they act as endocrine hormones of an enteric-renal system regulating salt and water homeostasis. ${ }^{27}$ Importantly, these peptides, exhibiting 15 (guanylin) or 16 (uroguanylin) residues and two intrachain disulfide bridges (Figure 1), selectively bind and activate GCC in apical brush-border membranes of intestinal epithelial cells, although with less potency than $\mathrm{ST}^{8,25,26}$ They are encoded by genes organized in a tail-to-tail configuration on human chromosome 1p, and secreted by intestinal mucosal cells as proforms, which are activated upon carboxyl terminus cleavage. ${ }^{8,28}$ Intriguingly, 
ligand effects appear to depend on extracellular $\mathrm{pH}$, and uroguanylin is 100-fold more potent than guanylin at acidic $\mathrm{pH}$ (5.0-5.5), while guanylin is fourfold more potent than uroguanylin at basic $\mathrm{pH}(8.0) .{ }^{29}$ Both endogenous GCC ligands exhibit a crypt-to-villus gradient of expression, which is maximal in small intestinal villi and superficial epithelial cells of the colon. ${ }^{28,30,31}$ However, uroguanylin is more abundant in the proximal tracts of the intestine, while guanylin is highly expressed in the colon and rectum. ${ }^{28,30,31}$ Also, guanylin and uroguanylin expression undergoes circadian rhythm (highest at night), ${ }^{32}$ is induced by osmotic stress $^{33}$ and zinc deficiency, ${ }^{34}$ and is downregulated by low salt intake. ${ }^{35}$ These regulatory mechanisms and distribution patterns of expression suggest a complex, spatially distinct role for these peptides in the intestine. In this context, guanylin and uroguanylin are considered autocrine/ paracrine hormones, which control local fluid balance and the homeostasis of the intestinal mucosa, including crypt renewal dynamics, cell differentiation and metabolism, and epithelial barrier function (Figure 2). 17,36 Their crucial function as promoters of the normal intestinal epithelial cell phenotype is further underscored by the GCC ligandopenia characterizing early colorectal carcinogenesis, ${ }^{37,38}$ and the anticancer activity of oral replacement therapy with GCC agonists in the gut. ${ }^{22}$

\section{Therapeutic drugs}

As our understanding of the number of critical physiological functions played by the biological ligands grows significantly (Figure 2), it is becoming apparent that GCC agonists possess great translational potential for human intestinal diseases. Currently, three artificial GCC ligands are being exploited

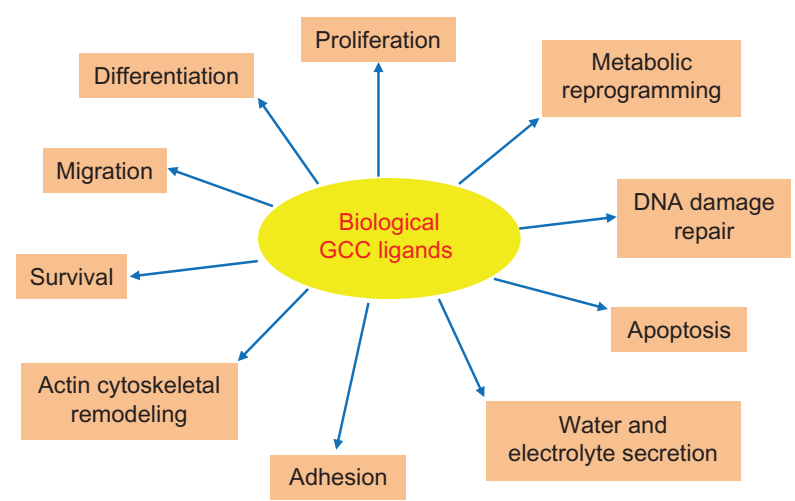

Figure 2 Physiological functions regulated by endogenous GCC agonists in the intestine.

Notes: The diagram indicates the principal putative biological responses elicited by endogenous hormones guanylin and uroguanylin upon binding and activation of GCC on intestinal brush-border membranes.

Abbreviation: GCC, guanylyl cyclase C. as oral therapeutics for chronic idiopathic constipation, constipation-predominant irritable bowel syndrome and IBD. The first synthetic GCC agonist entering the clinic has been linaclotide (Ironwood Pharmaceuticals Inc, Boston, MA, USA and Forest Laboratories Inc, New York, NY, USA), an ST analog cyclopeptide of 14 amino acids (Figure 1) which increases intestinal motility and fluid secretion, while decreasing visceral pain in preclinical models. ${ }^{9}$ Linaclotide is converted in vivo by carboxypeptidase A into the active 13 mer metabolite MM-419447, which contributes to linaclotide's pharmacodynamics. ${ }^{39}$ Recently, linaclotide has been approved in the US for the treatment of patients with chronic idiopathic constipation and irritable bowel syndrome with constipation, wherein this GCC agonist is behaving as a safe, reliable, and effective drug in improving disease-specific abdominal and bowel symptoms. ${ }^{39-42}$ In that context, a 26-week Phase III trial in 804 patients with constipation-predominant irritable bowel syndrome demonstrated that linaclotide ( $N$ of treated patients, 401) significantly ameliorated constipation and disease severity (clinical responders: linaclotide group, $33.7 \%$ versus placebo group, 13.9\%), while inducing significant, sustained improvement of worst abdominal pain and abdominal discomfort, fullness, cramping, and bloating. ${ }^{42}$ Of note, with the exception of diarrhea (mostly of mild/moderate intensity; linaclotide group, $19.7 \%$ versus placebo group, $2.5 \%$ ), which is an expected extension of linaclotide pharmacology, the incidence of adverse events was not significantly different in linaclotide-treated patients compared with the placebo controls..$^{42}$ After linaclotide, two additional artificial GCC agonists, plecanatide (a 16mer) (Figure 1) and SP-333 (Synergy Pharmaceuticals Inc, New York, NY, USA), have entered the drug developmental stage. ${ }^{10}$ Both synthetic analogs of uroguanylin, but of superior potency, plecanatide and SP-333 are exhibiting promises as gastrointestinal therapeutics. ${ }^{10}$ Plecanatide is in clinical development for the treatment of chronic idiopathic constipation (Phase IIb/III studies ongoing) and constipation-predominant irritable bowel syndrome (Phase I study planned). ${ }^{10}$ In the completed Phase I-II clinical trials, plecanatide significantly ameliorated patients' bowel movements and symptoms. ${ }^{10}$ In contrast, SP-333 is being investigated specifically for the treatment of IBD in patients with UC, and is currently in the preclinical stage of development. ${ }^{10}$ In studies employing animal models of IBD, SP-333 attenuated colitis-associated events through the downregulation of locally released autacoids mediating the inflammatory response. ${ }^{10}$ 


\section{Signal transduction mechanisms}

\section{The receptor}

The principal pharmacological target for ST, guanylin, uroguanylin, and their synthetic analogs is GCC. Discovered as the "heat stable enterotoxin receptor," ${ }^{15} \mathrm{GCC}$ is encoded by the gene GUCY2C on human chromosome 12p12. GUCY2C homologs are widely conserved across species including mammals, reptiles, and birds, suggesting a fundamental role for GCC in organismal biology. ${ }^{43-45}$ Beyond discrete neuronal cells in the central nervous system, ${ }^{46,47}$ in mammals, GCC is uniquely expressed at apical, brush-border membranes of intestinal epithelial cells from the duodenum to the rectum, uniformly distributed in crypts, villi, and mucosal surfaces. ${ }^{17}$ GCC, a member of membrane-bound guanylyl cyclases, is a homodimeric transmembrane enzyme exhibiting conserved functional domains (Figure 3A), including: (1) the extracellular domain for specific ligand binding; (2) a single transmembrane domain with an hydrophobic $\alpha$-helix region; (3) a short juxtamembrane domain with a G-protein consensus sequence; (4) the kinase homology domain, which binds adenosine triphosphate and regulates ligand-receptor affinity; (5) a hinge region, probably mediating catalytic subunit dimerization; (6) the catalytic domain, which mediates the conversion of guanosine triphosphate to cyclic guanosine monophosphate (cGMP); and (7) a carboxyl terminal tail with key regulatory functions, including modulation of cyclase activity, cytoskeletal anchoring, and receptor internalization. ${ }^{17}$ The extracellular domain of GCC possesses a unique amino acid sequence, and glycosylation and oligomerization sites, which affect the specificity, stability and efficacy of ligand-receptor binding. ${ }^{17}$ In this context, upon agonist binding to the extracellular domain of GCC, an intramolecular conformational change is induced and transmitted along the transmembrane and cytoplasmic domains to the carboxyl terminal catalytic site, resulting in a manifold increase of intracellular cGMP concentration over the basal state. ${ }^{15,17}$

\section{The downstream targets}

Cyclic GMP represents the sole intracellular second messenger for GCC agonists. A variety of key cellular responses are mediated by $\mathrm{cGMP},{ }^{17}$ which regulates virtually all major cytoplasmic signaling networks. ${ }^{48}$ In intestinal epithelial cells, GCC is the principal source of cGMP, and ligand-GCC interactions in concert with distinct elimination mechanisms (phosphodiesterase-dependent hydrolysis; transporter-dependent efflux) define the type, intensity, and duration of cellular cGMP rises and effects. In this way, elegant spatio-terminal determinants regulate crucial physiological responses in intestine by imposing maximal cGMP signaling. Examples of these include the increased endogenous ligand expression at superficial epithelial compartments, which mediates maturation dynamics, ${ }^{28,31}$ and the GCC baso-apical expression gradient within cells, which ensures fluid regulation at luminal membrane borders. ${ }^{17}$

The functional consequences of GCC agonist-induced cGMP elevations in intestinal epithelial cells reflect the selective targeting of downstream molecular effectors (Figure 3B), exhibiting two evolutionarily distinct allosteric binding sites for cGMP. One cGMP binding site is present in cGMP- and cAMP-dependent protein kinases (protein kinase $\mathrm{G}$ [PKG] and protein kinase A [PKA], respectively) and in cyclic nucleotide gated (CNG) cation channels, while the other is expressed in cGMP-regulated phosphodiesterases (PDEs). Differential tissue expression and intracellular compartmentalization of these cGMP targets enable
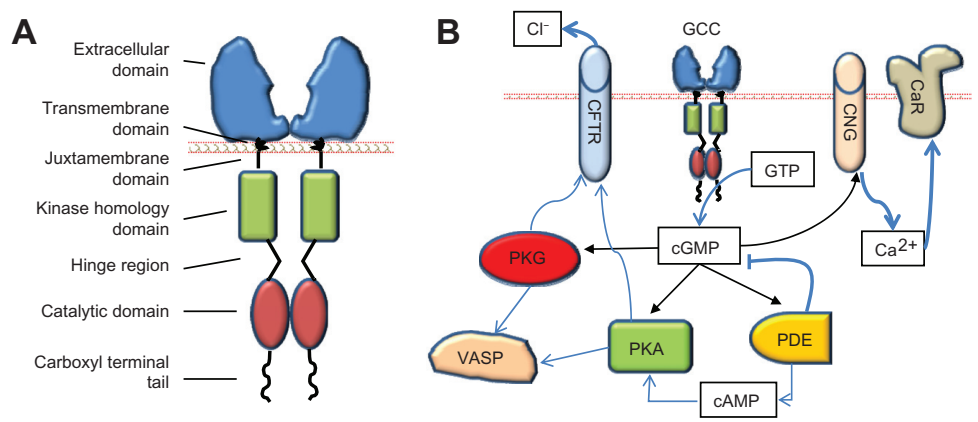

Figure 3 GCC and its downstream targets. (A) The domain structure of GCC. (B) Key proximal effectors activated by GCC in intestinal epithelial cells upon catalytic conversion of GTP to CGMP.

Abbreviations: cAMP, cyclic adenosine monophosphate; CaR, calcium-sensing receptor; CFTR, cystic fibrosis transmembrane conductance regulator; cGMP, cyclic guanosine monophosphate; CNG, cyclic nucleotide gated channel; GCC, guanylyl cyclase C; GTP, guanosine-5'-triphosphate; PDE, phosphodiesterases; PKA, protein kinase A; PKG, protein kinase G; VASP, vasodilator-stimulated phosphoprotein. 
selectivity and accuracy of signal transmission and execution. PKG and PKA principally mediate regulation of intestinal fluid homeostasis and cytoskeletal organization by GCC ligands at membrane regions (Figure 3B). PKG is a Ser/Thr protein kinase comprising two subtypes, the soluble PKG I, with two isoforms I $\alpha$ and $\mathrm{I} \beta$, widely expressed in tissues, and the particulate PKG II, abundant in the intestine. ${ }^{49} \mathrm{PKA}$ is a tetrameric kinase preferentially activated by cAMP. ${ }^{17}$ PKG II and PKA activation by GCC agonists mediate water and electrolyte secretion by inducing phosphorylation and opening of the cystic fibrosis transmembrane conductance regulator (CFTR), with subsequent $\mathrm{Cl}^{-}$efflux into the intestinal lumen. ${ }^{50-52}$ In this way, endogenous GCC ligands act as "fluidity sensors" that provide optimal intestinal mucosa hydration through induction of net secretion of water, $\mathrm{NaCl}$, and $\mathrm{HCO}_{3}-{ }^{-17} \mathrm{PKG} \mathrm{I}$, in turn, mediates effects of GCC ligands on the cytoskeleton and contractile apparatus. ${ }^{17}$ A particularly crucial PKG target in these actions is the vasodilator-stimulated phosphoprotein (VASP), an actin binding protein controlling cytoskeletal remodeling, cell shape, and adhesion contacts in intestinal epithelial cells. ${ }^{53}$ Herein, GCC agonists induce rapid PKG I-mediated phosphorylation of Ser239 in the carboxyl terminal VASP domain, ${ }^{54}$ thereby suppressing F-actin polymerization and membrane protrusion formation. $.3,55,56$

Further, CNG channels represent a principal intracellular effector for inhibition of proliferation by GCC agonists in intestine (Figure 3B). CNG channels are heterotetrameric proteins of $\alpha$ - and $\beta$-subunits, which mediate cGMPdependent $\mathrm{Na}^{+}$and $\mathrm{Ca}^{2+}$ influx. ${ }^{57} \mathrm{GCC}$ signaling through $\mathrm{CNG}$ channels slows intestinal cell cycle progression by inducing intracellular $\mathrm{Ca}^{2+}$ influx and cytosolic $\mathrm{Ca}^{2+}$ elevations. ${ }^{21} \mathrm{An}$ important mechanism by which intracellular $\mathrm{Ca}^{2+}$ by $\mathrm{GCC}$ agonists suppresses proliferation in intestinal cells is the translocation of calcium-sensing receptors to membrane compartments ${ }^{58}$ Calcium-sensing receptor is a key mediator of tumor inhibitory activities by luminal $\mathrm{Ca}^{2+}$, principally reflecting its role as a regulator of intestinal cell maturation dynamics. Thus, ligand-GCC signaling may act as a regulatory system promoting physiological actions by dietary $\mathrm{Ca}^{2+}$ in the gut, including cytostasis and the proliferation to differentiation transition along the crypt-villus axis..$^{21,58}$ Finally, cGMP-regulated PDEs (eg, PDE2, PDE5, PDE6, and PDE10) are enzymes specialized in the cleavage of the cyclic nucleotide phosphodiester bond. ${ }^{17}$ In intestinal epithelial cells, these PDEs are principally involved in the modulation or termination of biological signaling by GCC agonists, and in the cross-talk between cGMP- and cAMP-dependent pathways (Figure 3B)..$^{22,59}$

\section{GCC signaling in colonic mucosal integrity}

During the last decade, the appreciation of the biological significance of GCC and its ligands for intestinal mucosa homeostasis is increased substantially (Figure 2), and from a mere fluidity sensor mechanism, the agonist/GCC pathway may now be considered a fundamental promoter of the intestinal mucosa integrity and its dependent barrier function. In this regard, the columnar epithelial cell monolayer covering the inner surface of the colorectum provides a complex chemical and physical barrier protecting the host from its harmful external environment, including pathogens, toxins, and food bioproducts. ${ }^{60}$ This monolayer is sealed by tight junctions restricting barrier permeability and comprises three cell lineages arising from self-perpetuating stem cells located at colonic crypt bases, including absorptive colonocytes, mucus-producing goblet cells, and hormone-secreting enteroendocrine cells. ${ }^{61}$ Maintenance of the balance between proliferation, migration, and differentiation along the colonic crypt-surface axis is central in preserving an intact epithelial barrier function, and alterations in those cell homeostatic dynamics compromise the bowel mucosal integrity, thereby favoring inflammatory responses and IBD by unchecked exposure of the sterile host compartment to dangerous luminal antigens. ${ }^{62}$ Elimination of GCC signaling disrupts the epithelial lineage crypt-surface balance in the mouse colon, reflected by hyperplastic proliferative compartments with fast-cycling and fast-migrating progenitor cells, ${ }^{63,64}$ and poorly developed differentiated compartments, characterized by incomplete phenotypic and metabolic maturation and selfrepair programs. ${ }^{64-66}$ In particular, loss of GCC resulted in a fewer number of colonic goblet cells, with reduced production of mucin and intestinal trefoil factor. ${ }^{64}$ This is significant because UC patients exhibit fewer, malfunctioning goblet cells whose pathological recapitulation in mouse models results in loss of mucosal integrity, inflammation, and spontaneous colitis ${ }^{67}$ Moreover, mucin and intestinal trefoil factor are key components of the gut-coating mucus layer mediating epithelial barrier protection and post-injury restitution, and their defective production or activity in mice causes increased intestinal permeability and susceptibility to chronic colonic inflammation. ${ }^{68}$ The contribution to optimal mucus barrier function is further underscored by the ability of ligand-dependent GCC signaling through CFTR to 
induce secretion of $\mathrm{NaCl}$ and $\mathrm{HCO}_{3}^{-},{ }^{-17,50}$ critical electrolytes controlling the rheological properties of the mucus layer and its proper interaction with the adjacent colonic microbiota. ${ }^{69}$ Importantly, secretion of these electrolytes at colonic surfaces is often dysregulated in UC patients. ${ }^{70}$

Beyond effects on lineage- and mucus-dependent functions, GCC signaling protects intestinal barrier integrity by promoting tight junction-mediated epithelial cell sealing. Elimination of GCC or uroguanylin in mice increased intestinal permeability and inflammation through myosin light chain kinase activation and tight junction disassembly, with reduced claudin-2 and JAM-A levels. ${ }^{13}$ Accordingly, induction of GCC signaling with GCC agonists enhanced tight junction assembly, reduced intestinal barrier permeability and protected mice from chemical-induced colitis. ${ }^{14} \mathrm{~A}$ key mechanism mediating regulation of epithelial cell tight junctions by GCC is the inhibition of v-akt murine thymoma viral oncogene homolog 1 (AKT-1) activity, coupled with increased expression of junctional proteins occludin and claudin- $4 .{ }^{14}$ In this context, it is reasonable to speculate that the likely candidate as the proximal molecular effector of GCC-mediated intestinal barrier functions is PKG. In support of this notion, PKG I-mediated VASP phosphorylation represents a well established paradigm underlying cell-cell junction integrity and tissue barrier protection. ${ }^{71,72}$ Notably, in intestinal epithelial cells, GCC agonists suppress cytoskeletal remodeling at dynamic membrane regions, the process driving epithelial junction disassembly, ${ }^{73}$ by inducing PKG-dependent VASP phosphorylation. ${ }^{53}$ Moreover, ligandmediated GCC signaling through CFTR, which controls electrolyte secretion and intestinal barrier maintenance by the mucus layer, is a PKG II-dependent phenomenon. ${ }^{17,50}$ Together, these observations underscore the central role of the GCC pathway in support of intestinal barrier integrity, including its protection from or its restitution following injury. In one model, similarly to other intestinal regulatory peptides, GCC endogenous ligands guanylin and uroguanylin are to be considered "mucosal barrier guardians," whose signal transduction dysregulation may contribute to inflammation and IBD. ${ }^{74}$ Conversely, iatrogenic induction of colonic GCC signaling with administration of specific agonists as therapeutics may hold great promise for the prevention of further damage, or mucosal barrier restitution in patients with UC (Figure 4). ${ }^{10,14}$

\section{GCC agonists as UC therapeutics}

Current pharmacological remedies for UC include 5-aminosalicylic acid, corticosteroids, cyclosporine,

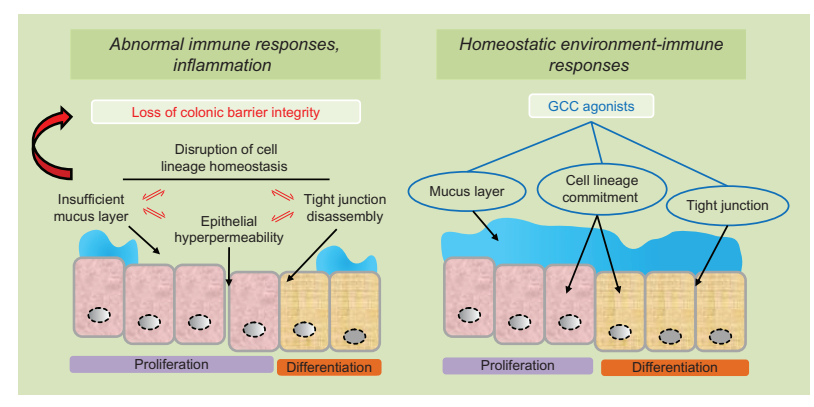

Figure $4 \mathrm{GCC}$ agonists as ulcerative colitis therapeutics.

Notes: In ulcerative colitis, abnormal immune responses and colonic inflammation reflect inappropriate luminal antigen exposure for disruption of the mucosal barrier integrity (left panel). Pathogenetic mechanisms underlying loss of intestinal barrier function, in turn, include mutually reinforcing processes of cell lineage imbalance, defective mucus layer, tight junction disassembly and epithelial cell hyper-permeability (left panel). Administration of GCC agonists reconstitutes normal environmentimmune interactions by restoring the colonic mucosal barrier integrity, in part, through the promotion of cell lineage-dependent homeostasis, optimal superficial mucus layer and epithelial cells' tight junctions (right panel).

Abbreviation: GCC, guanylyl cyclase C.

and infliximab, a monoclonal antibody blocking proinflammatory tumor necrosis factor- $\alpha .{ }^{1}$ Although these drugs may induce symptom remission and successfully prevent disease progression, ${ }^{75} \sim 30 \%$ of patients with severe $\mathrm{UC}$ are resistant to pharmacological therapy and require colectomy. ${ }^{76,77}$ The global risk of colectomy for UC patients is $\sim 9 \%$ over 10 years. ${ }^{76}$ Common curative surgery consists of total proctocolectomy with ileal J-pouch anal anastomosis. ${ }^{76}$ However, this procedure is associated with high rates $(\sim 20 \%)$ of postoperative complications, ${ }^{76}$ including abscesses, sepsis, fistulas, infertility, and sexual dysfunction. ${ }^{78,79}$ Thus, innovative drug development programs for UC are warranted. In that context, GCC agonists could be exploited as a unique class of therapeutics for IBD and UC in particular. In the "leaky gut" hypothesis, intestinal hyper-permeability resulting from disruption of mucosal barrier integrity is a principal pathogenetic event underlying abnormal immune responses to luminal antigen exposure and IBD (Figure 4, left panel). ${ }^{60,62,80,81}$ Reestablishment of epithelial barrier function, in turn, could arrest pathogenetic processes of inflammation thereby preventing or treating IBD. ${ }^{81}$ As GCC signaling protects lineage-dependent homeostasis along the colonic crypt-surface axis, ${ }^{36,64}$ activation of that pathway by its specific ligands could restore normal environmentimmune interactions regulated by the epithelial monolayer (Figure 4, right panel). ${ }^{60}$ Moreover, the ability of GCC agonists to specifically reinforce the colonic barrier through the regulation of the superficial mucus layer ${ }^{17,50}$ and epithelial tight junctions ${ }^{14}$ may predict their utility as novel drugs for the chemoprevention and treatment of patients with barrier-dependent intestinal inflammation (Figure 4). ${ }^{62,81}$ 
Additionally, expression of endogenous GCC ligands guanylin and uroguanylin is significantly reduced in affected UC tissues compared with healthy subjects, ${ }^{82}$ supporting the notion that restoration of the dormant GCC pathway with exogenous administration of GCC agonists may be an effective strategy to tissue restitution in UC patients.

In striking contrast with the above considerations, a nonsynonymous single nucleotide polymorphism in GUCY2C conferred a dominant phenotype on affected members of a Norwegian family, characterized by liganddependent hyperactivation of GCC signaling, chronic diarrhea, and susceptibility to intestinal inflammation and IBD..$^{83}$ Accordingly, $\sim 10 \%$ of travelers experiencing acute diarrhea from exposure to Escherichia coli producing the GCC super-agonist ST develop post-infectious chronic intestinal symptoms and irritable bowel syndrome. ${ }^{84}$ Further, the artificial ST analog linaclotide compared poorly with other drugs in protecting isolated pig jejunum from ischemia-induced intestinal barrier disruption, ${ }^{85}$ and mice deficient in $G U C Y 2 C$ exhibited reduced mucosal damage and inflammation following chemical-induced colitis. ${ }^{86}$ Beyond confounding variability in experimental models, apparent conflicting observations on the role of GCC in inflammatory gut disorders could be reconciled if one assumes that only physiological levels of ligand-dependent GCC activation mediate intestinal mucosa protection. In this model, activation of the wild-type GCC receptor with the endogenous ligands ensures beneficial GCC signaling underlying normal intestinal biology. In contrast, both dormancy and hyperactivation of the GCC pathway would disrupt mucosal homeostasis and result in bowel disease susceptibility. Thus, administration of adequate dosages of GCC agonists should mimic homeostatic functions of endogenous ligands and oppose intestinal barrier disruption, prevent inflammatory responses and treat IBD-associated pathological events. Of significance, SP-333, the GCC agonist currently under therapeutic development for the treatment of patients with UC, is an artificial analog of the endogenous GCC ligand uroguanylin. ${ }^{10} \mathrm{SP}-333$ is behaving as a highly effective drug in preclinical mouse models of UC, wherein it is reducing colonic inflammatory damage induced with various chemicals, in part, through the downregulation of proinflammatory cytokines including interleukins 4, 5, and 23, and tumor necrosis factor. ${ }^{10}$ Finally, prolonged stimulation of GCC with its ligands produces cellular refractoriness to biological effects of GCC agonists, ${ }^{59}$ pointing toward selective temporal administration schedules as yet another critical variable, apart from drug concentrations, to consider for optimal translation of GCC-targeted strategies into UC patients' therapeutics.

\section{Conclusion}

In UC, disruption of homeostatic balance between intestinal microflora, epithelial barrier permeability and host immune responses underlies colitis and tissue damage. 5,6 It is suggested that unsupervised exposure of the sterile subepithelial compartment to luminal antigens promotes chronic inflammatory processes and recurrent symptoms. ${ }^{62}$ There is a need for innovative drug development programs in $\mathrm{UC}$, wherein $\sim 9 \%$ of patients undergo colectomy as a result of severe disease that is resistant to current pharmacological therapy. ${ }^{1,76}$ GCC agonists are attractive novel UC therapeutics because of their unique mechanism of action, which would enable restoration of homeostatic signaling circuits promoting colonic mucosa integrity. In this way, GCC agonists will fill an unmet need in the pharmacological anti-UC armamentarium by targeting one causal mechanism of chronic colonic inflammation, abnormal mucosal permeability. ${ }^{81}$

Beyond inflammation in the gut, intestinal barrier protection by GCC and its agonists also reduces local and systemic DNA damage and tumorigenesis. ${ }^{14,65}$ Not surprisingly, UC patients exhibit a higher incidence of colorectal cancer. ${ }^{1}$ An inverse epidemiological association exists between colon cancer and the risk for enterotoxigenic infections, ${ }^{21}$ and UC is less common in geographic areas where those infections are endemic. ${ }^{2}$ Thus, it is tempting to speculate that intermittent longitudinal exposure to the exogenous GCC agonist ST may contribute to protect resident populations from both $\mathrm{UC}$ and colorectal cancer. These observations also suggest that GCC agonists might have a broad therapeutic utility, from local inflammation and tumorigenesis chemoprevention to systemic protective actions against genotoxicity and transformation. ${ }^{14}$ Of relevance, oral administration of GCC agonists is a safe, effective, and well tolerated medication in patients with chronic constipation, ${ }^{39-42}$ underscoring the clinical utility for these agents as human therapeutics. Together, these considerations support the great significance and translational potential of GCC agonists for the management of UC patients, reflecting the emergent role of this new class of drugs as promoters and protectors of the mucosal barrier integrity in the colon.

\section{Acknowledgment}

This work was supported by a grant from the American Institute for Cancer Research. 


\section{Disclosure}

The author has no conflicts of interest to declare in relation to the topics and content discussed in this review.

\section{References}

1. Langan RC, Gotsch PB, Krafczyk MA, Skillinge DD. Ulcerative colitis: diagnosis and treatment. Am Fam Physician. 2007;76(9):1323-1330.

2. Lakatos PL. Recent trends in the epidemiology of inflammatory bowel diseases: up or down? World J Gastroenterol. 2006;12(38): 6102-6108.

3. Blumberg RS, Strober W. Prospects for research in inflammatory bowel disease. JAMA. 2001;285(5):643-647.

4. Podolsky DK. Inflammatory bowel disease. N Engl J Med. 2002; 347(6):417-429.

5. Xavier RJ, Podolsky DK. Unravelling the pathogenesis of inflammatory bowel disease. Nature. 2007;448(7152):427-434.

6. Sartor RB. Mechanisms of disease: pathogenesis of Crohn's disease and ulcerative colitis. Nat Clin Pract Gastroenterol Hepatol. 2006; 3(7):390-407.

7. Guerrant RL, Hughes JM, Chang B, Robertson DC, Murad F. Activation of intestinal guanylate cyclase by heat-stable enterotoxin of Escherichia coli: studies of tissue specificity, potential receptors, and intermediates. J Infect Dis. 1980;142(2):220-228.

8. Forte LR. Guanylin regulatory peptides: structures, biological activities mediated by cyclic GMP and pathobiology. Regul Pept. 1999; 81(1-3):25-39.

9. Harris LA, Crowell MD. Linaclotide, a new direction in the treatment of irritable bowel syndrome and chronic constipation. Curr Opin Mol Ther. 2007;9(4):403-410.

10. synergypharma.com [homepage on the Internet]. New York, NY: Synergy Pharmaceuticals, Inc. 2013. Available from: http://www. synergypharma.com. Accessed January 14, 2013.

11. Guarino A, Cohen MB, Giannella RA. Small and large intestinal guanylate cyclase activity in children: effect of age and stimulation by Escherichia coli heat-stable enterotoxin. Pediatr Res. 1987;21(6):551-555.

12. Waldman SA, O’Hanley P, Falkow S, Schoolnik G, Murad F. A simple, sensitive, and specific assay for the heat-stable enterotoxin of Escherichia coli. J Infect Dis. 1984;149(1):83-89.

13. Han X, Mann E, Gilbert S, et al. Loss of guanylyl cyclase C (GCC) signaling leads to dysfunctional intestinal barrier. PLoS One. 2011; 6(1):e16139.

14. Lin JE, Snook AE, Li P, et al. GUCY2C opposes systemic genotoxic tumorigenesis by regulating AKT-dependent intestinal barrier integrity. PLoS One. 2012;7(2):e31686.

15. Schulz S, Green CK, Yuen PS, Garbers DL. Guanylyl cyclase is a heat-stable enterotoxin receptor. Cell. 1990;63(5):941-948.

16. Schmitt CK, Meysick KC, O’Brien AD. Bacterial toxins: friends or foes? Emerg Infect Dis. 1999;5(2):224-234.

17. Lucas KA, Pitari GM, Kazerounian S, et al. Guanylyl cyclases and signaling by cyclic GMP. Pharmacol Rev. 2000;52(3):375-414.

18. Mann EA, Jump ML, Wu J, Yee E, Giannella RA. Mice lacking the guanylyl cyclase $\mathrm{C}$ receptor are resistant to STa-induced intestinal secretion. Biochem Biophys Res Commun. 1997;239(2):463-466.

19. Schulz S, Lopez MJ, Kuhn M, Garbers DL. Disruption of the guanylyl cyclase-C gene leads to a paradoxical phenotype of viable but heat-stable enterotoxin-resistant mice. J Clin Invest. 1997;100(6):1590-1595.

20. Pawlowski SW, Warren CA, Guerrant R. Diagnosis and treatment of acute or persistent diarrhea. Gastroenterology. 2009;136(6):1874-1886.

21. Pitari GM, Zingman LV, Hodgson DM, et al. Bacterial enterotoxins are associated with resistance to colon cancer. Proc Natl Acad Sci US A. 2003;100(5):2695-2699.

22. Shailubhai K, Yu HH, Karunanandaa K, et al. Uroguanylin treatment suppresses polyp formation in the $\operatorname{Apc}(\mathrm{Min} /+)$ mouse and induces apoptosis in human colon adenocarcinoma cells via cyclic GMP. Cancer Res. 2000;60(18):5151-5157.
23. Pitari GM, Di Guglielmo MD, Park J, Schulz S, Waldman SA. Guanylyl cyclase $\mathrm{C}$ agonists regulate progression through the cell cycle of human colon carcinoma cells. Proc Natl Acad Sci U S A. 2001;98(14):7846-7851.

24. Currie MG, Fok KF, Kato J, et al. Guanylin: an endogenous activator of intestinal guanylate cyclase. Proc Natl Acad Sci U S A. 1992; 89(3):947-951.

25. Hamra FK, Forte LR, Eber SL, et al. Uroguanylin: structure and activity of a second endogenous peptide that stimulates intestinal guanylate cyclase. Proc Natl Acad Sci U S A. 1993;90(22):10464-10468.

26. Kita T, Smith CE, Fok KF, et al. Characterization of human uroguanylin: a member of the guanylin peptide family. Am J Physiol. 1994; 266(2 Pt 2):F342-F348.

27. Kuhn M. Molecular physiology of natriuretic peptide signalling. Basic Res Cardiol. 2004;99(2):76-82.

28. Cohen MB, Hawkins JA, Witte DP. Guanylin mRNA expression in human intestine and colorectal adenocarcinoma. Lab Invest. 1998; 78(1):101-108.

29. Hamra FK, Eber SL, Chin DT, Currie MG, Forte LR. Regulation of intestinal uroguanylin/guanylin receptor-mediated responses by mucosal acidity. Proc Natl Acad Sci U S A. 1997;94(6):2705-2710.

30. Cohen MB, Witte DP, Hawkins JA, Currie MG. Immunohistochemical localization of guanylin in the rat small intestine and colon. Biochem Biophys Res Commun. 1995;209(3):803-808.

31. Whitaker TL, Witte DP, Scott MC, Cohen MB. Uroguanylin and guanylin: distinct but overlapping patterns of messenger RNA expression in mouse intestine. Gastroenterology. 1997;113(3):1000-1006.

32. Scheving LA, Jin WH. Circadian regulation of uroguanylin and guanylin in the rat intestine. Am J Physiol. 1999;277(6 Pt 1): C1177-C1183.

33. Steinbrecher KA, Rudolph JA, Luo G, Cohen MB. Coordinate upregulation of guanylin and uroguanylin expression by hypertonicity in HT29-18-N2 cells. Am J Physiol. 2002;283(6):C1729-C1737.

34. Blanchard RK, Cousins RJ. Upregulation of rat intestinal uroguanylin mRNA by dietary zinc restriction. Am J Physiol. 1997;272(5 Pt 1): G972-G978.

35. Li Z, Knowles JW, Goyeau D, et al. Low salt intake down-regulates the guanylin signaling pathway in rat distal colon. Gastroenterology. 1996;111(6):1714-1721.

36. Pitari GM, Li P, Lin JE, et al. The paracrine hormone hypothesis of colorectal cancer. Clin Pharmacol Ther. 2007;82(4):441-447.

37. Steinbrecher KA, Tuohy TM, Heppner Goss K, et al. Expression of guanylin is downregulated in mouse and human intestinal adenomas. Biochem Biophys Res Commun. 2000;273(1):225-230.

38. Notterman DA, Alon U, Sierk AJ, Levine AJ. Transcriptional gene expression profiles of colorectal adenoma, adenocarcinoma, and normal tissue examined by oligonucleotide arrays. Cancer Res. 2001; 61(7):3124-3130.

39. Busby RW, Kessler MM, Bartolini WP, et al. Pharmacologic properties, metabolism, and disposition of linaclotide, a novel therapeutic peptide approved for the treatment of irritable bowel syndrome with constipation and chronic idiopathic constipation. J Pharmacol Exp Ther. 2013;344(1):196-206.

40. Rao S, Lembo AJ, Shiff SJ, et al. A 12-week, randomized, controlled trial with a 4-week randomized withdrawal period to evaluate the efficacy and safety of linaclotide in irritable bowel syndrome with constipation. Am J Gastroenterol. 2012;107(11):1714-1724.

41. Andresen V, Camilleri M, Busciglio IA, et al. Effect of 5 days linaclotide on transit and bowel function in females with constipation-predominant irritable bowel syndrome. Gastroenterology. 2007;133(3):761-768.

42. Chey WD, Lembo AJ, Lavins BJ, et al. Linaclotide for irritable bowel syndrome with constipation: a 26-week, randomized, double-blind, placebo-controlled trial to evaluate efficacy and safety. Am J Gastroenterol. 2012;107(11):1702-1712.

43. Krause WJ, Cullingford GL, Freeman RH, et al. Distribution of heat-stable enterotoxin/guanylin receptors in the intestinal tract of man and other mammals. J Anat. 1994;184(Pt 2):407-417. 
44. Krause WJ, Freeman RH, Eber SL, Hamra FK, Currie MG, Forte LR. Guanylyl cyclase receptors and guanylin-like peptides in reptilian intestine. Gen Comp Endocrinol. 1997;107(2):229-239.

45. Krause WJ, Freeman RH, Eber SL, et al. Distribution of Escherichia coli heat-stable enterotoxin/guanylin/uroguanylin receptors in the avian intestinal tract. Acta Anat. 1995;153(3):210-219.

46. Gong R, Ding C, Hu J, et al. Role for the membrane receptor guanylyl cyclase-C in attention deficiency and hyperactive behavior. Science. 2011;333(6049):1642-1646.

47. Valentino MA, Lin JE, Snook AE, et al. A uroguanylin-GUCY2C endocrine axis regulates feeding in mice. $J$ Clin Invest. 2011;121(9): 3578-3588.

48. Bryan NS, Bian K, Murad F. Discovery of the nitric oxide signaling pathway and targets for drug development. Front Biosci. 2009;14:1-18.

49. Pfeifer A, Ruth P, Dostmann W, Sausbier M, Klatt P, Hofmann F. Structure and function of cGMP-dependent protein kinases. Rev Physiol Biochem Pharmacol. 1999;135:105-149.

50. Vaandrager AB, Bot AG, De Jonge HR. Guanosine $3^{\prime}, 5^{\prime}$ cyclic monophosphate-dependent protein kinase II mediates heat-stable enterotoxin-provoked chloride secretion in rat intestine. Gastroenterology. 1997;112(2):437-443.

51. Chao AC, de Sauvage FJ, Dong YJ, Wagner JA, Goeddel DV, Gardner P. Activation of intestinal CFTR Cl- channel by heat-stable enterotoxin and guanylin via cAMP-dependent protein kinase. $E M B O J$. 1994;13(5):1065-1072.

52. Vaandrager AB, Bot AG, Ruth P, Pfeifer A, Hofmann F, De Jonge HR. Differential role of cyclic GMP-dependent protein kinase II in ion transport in murine small intestine and colon. Gastroenterology. 2000;118(1):108-114.

53. Zuzga DS, Pelta-Heller J, Li P, Bombonati A, Waldman SA, Pitari GM. Phosphorylation of vasodilator-stimulated phosphoprotein Ser239 suppresses filopodia and invadopodia in colon cancer. Int $J$ Cancer. 2012;130(11):2539-2548.

54. Deguchi A, Soh JW, Li H, Pamukcu R, Thompson WJ, Weinstein IB. Vasodilator-stimulated phosphoprotein (VASP) phosphorylation provides a biomarker for the action of exisulind and related agents that activate protein kinase G. Mol Cancer Ther 2002;1(10):803-809.

55. Benz PM, Blume C, Seifert S, et al. Differential VASP phosphorylation controls remodeling of the actin cytoskeleton. J Cell Sci. 2009; 122(Pt 21):3954-3965.

56. Lindsay SL, Ramsey S, Aitchison M, Renne T, Evans TJ. Modulation of lamellipodial structure and dynamics by NO-dependent phosphorylation of VASP Ser239. J Cell Sci. 2007;120(Pt 17): 3011-3021.

57. Biel M, Zong X, Ludwig A, Sautter A, Hofmann F. Structure and function of cyclic nucleotide-gated channels. Rev Physiol Biochem Pharmacol. 1999;135:151-171.

58. Pitari GM, Lin JE, Shah FJ, et al. Enterotoxin preconditioning restores calcium-sensing receptor-mediated cytostasis in colon cancer cells. Carcinogenesis. 2008;29(8):1601-1607.

59. Pitari GM, Baksh RI, Harris DM, Li P, Kazerounian S, Waldman SA. Interruption of homologous desensitization in cyclic guanosine $3^{\prime}, 5^{\prime}$ monophosphate signaling restores colon cancer cytostasis by bacterial enterotoxins. Cancer Res. 2005;65(23):11129-11135.

60. Moens E, Veldhoen M. Epithelial barrier biology: good fences make good neighbours. Immunology. 2012;135(1):1-8.

61. Potten CS, Booth C, Pritchard DM. The intestinal epithelial stem cell: the mucosal governor. Int J Exp Pathol. 1997;78(4):219-243.

62. Sanders DS. Mucosal integrity and barrier function in the pathogenesis of early lesions in Crohn's disease. J Clin Pathol. 2005;58(6): $568-572$.

63. Steinbrecher KA, Wowk SA, Rudolph JA, Witte DP, Cohen MB. Targeted inactivation of the mouse guanylin gene results in altered dynamics of colonic epithelial proliferation. Am J Pathol. 2002; 161(6):2169-2178.
64. Li P, Lin JE, Chervoneva I, Schulz S, Waldman SA, Pitari GM Homeostatic regulation of the crypt-to-villus axis by the bacterial enterotoxin receptor guanylyl cyclase $\mathrm{C}$ restricts the proliferating compartment in intestine. Am J Pathol. 2007;171(6):1847-1858.

65. Li P, Schulz S, Bombonati A, et al. Guanylyl cyclase C suppresses intestinal tumorigenesis by restricting proliferation and maintaining genomic integrity. Gastroenterology. 2007;133(2):599-607.

66. Lin JE, Li P, Snook AE, et al. The hormone receptor GUCY2C suppresses intestinal tumor formation by inhibiting AKT signaling. Gastroenterology. 2010;138(1):241-254.

67. Heazlewood CK, Cook MC, Eri R, et al. Aberrant mucin assembly in mice causes endoplasmic reticulum stress and spontaneous inflammation resembling ulcerative colitis. PLoS Med. 2008; 5(3):e54.

68. Kim YS, Ho SB. Intestinal goblet cells and mucins in health and disease: recent insights and progress. Curr Gastroenterol Rep. 2010;12(5): 319-330.

69. Bachmann O, Seidler U. News from the end of the gut - how the highly segmental pattern of colonic $\mathrm{HCO}(3)(-)$ transport relates to absorptive function and mucosal integrity. Biol Pharm Bull. 2011;34(6): 794-802.

70. Sandle GI, Higgs N, Crowe P, Marsh MN, Venkatesan S, Peters TJ. Cellular basis for defective electrolyte transport in inflamed human colon. Gastroenterology. 1990;99(1):97-105.

71. Wojciak-Stothard B, Torondel B, Zhao L, Renne T, Leiper JM. Modulation of Rac1 activity by ADMA/DDAH regulates pulmonary endothelial barrier function. Mol Biol Cell. 2009;20(1):33-42.

72. Schlegel N, Waschke J. Vasodilator-stimulated phosphoprotein: crucial for activation of Rac1 in endothelial barrier maintenance. Cardiovasc Res. 2010;87(1):1-3.

73. Ivanov AI, McCall IC, Parkos CA, Nusrat A. Role for actin filament turnover and a myosin II motor in cytoskeleton-driven disassembly of the epithelial apical junctional complex. Mol Biol Cell. 2004;15(6): 2639-2651.

74. Sturm A, Dignass AU. Epithelial restitution and wound healing in inflammatory bowel disease. World J Gastroenterol. 2008;14(3): 348-353.

75. Keyashian K, Annunziata ML, Sakuraba A, Hanauer S. Management of inflammatory bowel disease: past, present and future. Expert Rev Clin Immunol. 2012;8(4):303-305.

76. Meier J, Sturm A. Current treatment of ulcerative colitis. World $J$ Gastroenterol. 2011;17(27):3204-3212.

77. Jenkins HR. Inflammatory bowel disease. Arch Dis Child. 2001;85(5): 435-437.

78. Loftus EV Jr, Delgado DJ, Friedman HS, Sandborn WJ. Colectomy and the incidence of postsurgical complications among ulcerative colitis patients with private health insurance in the United States. Am $J$ Gastroenterol. 2008;103(7):1737-1745.

79. Waljee A, Waljee J, Morris AM, Higgins PD. Threefold increased risk of infertility: a meta-analysis of infertility after ileal pouch anal anastomosis in ulcerative colitis. Gut. 2006;55(11):1575-1580.

80. Turner JR. Intestinal mucosal barrier function in health and disease. Nat Rev Immunol. 2009;9(11):799-809.

81. Fasano A. Zonulin and its regulation of intestinal barrier function: the biological door to inflammation, autoimmunity, and cancer. Physiol Rev. 2011;91(1):151-175.

82. Wu F, Dassopoulos T, Cope L, et al. Genome-wide gene expression differences in Crohn's disease and ulcerative colitis from endoscopic pinch biopsies: insights into distinctive pathogenesis. Inflamm Bowel Dis. 2007;13(7):807-821.

83. Fiskerstrand T, Arshad N, Haukanes BI, et al. Familial diarrhea syndrome caused by an activating GUCY2C mutation. $N$ Engl $J$ Med. 2012;366(17):1586-1595.

84. Okhuysen PC, Jiang ZD, Carlin L, Forbes C, DuPont HL. Post-diarrhea chronic intestinal symptoms and irritable bowel syndrome in North American travelers to Mexico. Am J Gastroenterol. 2004;99(9): 1774-1778. 
85. Cuppoletti J, Blikslager AT, Chakrabarti J, Nighot PK, Malinowska DH. Contrasting effects of linaclotide and lubiprostone on restitution of epithelial cell barrier properties and cellular homeostasis after exposure to cell stressors. BMC Pharmacol. 2012;12(1):3.
86. Steinbrecher KA, Harmel-Laws E, Garin-Laflam MP, et al. Murine guanylate cyclase $\mathrm{C}$ regulates colonic injury and inflammation. J Immunol. 2011;186(12):7205-7214.

\section{Publish your work in this journal}

Drug Design, Development and Therapy is an international, peerreviewed open-access journal that spans the spectrum of drug design and development through to clinical applications. Clinical outcomes, patient safety, and programs for the development and effective, safe, and sustained use of medicines are a feature of the journal, which has also been accepted for indexing on PubMed Central. The manuscript management system is completely online and includes a very quick and fair peer-review system, which is all easy to use. Visit http://www.dovepress.com/testimonials.php to read real quotes from published authors.

Submit your manuscript here: http://www.dovepress.com/drug-design-development-and-therapy-journal 